\title{
Pengaruh Model Problem Based Learning Berbantuan Software Cabri 3D V2 terhadap Kemampuan Literasi Numerasi Siswa
}

\author{
Elok Rintarti Widiastuti ${ }^{1}$, Meyta Dwi Kurniasih ${ }^{2}$ \\ ${ }^{1,2}$ Program Studi Pendidikan Matematika, Fakultas Ilmu Pendidikan, Universitas Muhammadiyah Prof. Dr. HAMKA, \\ Jl. Tanah Merdeka No 20, Jakarta Timur, Indonesia \\ rintartielok@gmail.com
}

\begin{abstract}
This research focused on revealing the effect of the problem-based learning model assisted by Cabri 3D V2 on students' numeracy literacy skills. The population of this study was grade 8 students at the State Junior High School 5 Tambun Selatan and the sample was determined using a cluster random sampling technique with the selection of class $8.8(\mathrm{H})$ as the control class and class 8.9 (I) as the experimental class and carried out in the even semester $2020 / 2021$ of the academic year. Its method is quasi-experimental with a quantitative approach and takes the form of a posttest-only control group design. The class selection still takes into account the normality and homogeneity of the two selected classes. The data analysis technique used the test and observation method. Its results reveal that the coefficient of impact for the problem-based learning model assisted by the Cabri 3D V2 software can increase numeracy literacy skills in the amount of 1.237538. For further researchers, to examine the use of other learning models assisted by other mathematical software or to find out whether there is an effect on increasing students' numeracy literacy skills at the junior high school/equivalent level.
\end{abstract}

Keywords: Numeracy literacy skills, problem-based learning models, cabri 3D V2 software

\begin{abstract}
Abstrak
Fokus penelitian ini adalah untuk mengungkapkan pengaruh model problem-based learning berbantuan Cabri $3 D$ $V 2$ terhadap kemampuan literasi numerasi siswa. Penelitian ini mengambil populasi siswa kelas 8 Sekolah Menengah Pertama Negeri 5 Tambun Selatan dan sampelnya ditentukan menggunakan teknik cluster random sampling dengan terpilihnya kelas $8.8(\mathrm{H})$ sebagai kelas kontrol dan kelas 8.9 (I) sebagai kelas eksperimen dan dilaksanakan pada semester genap tahun ajaran 2020/2021. Metode penelitian ini adalah eksperimen semu dengan pendekatan kuantitatif dan mengambil bentuk posttest only control group design. Pemilihan kelas tersebut tetap memperhatikan normal dan homogen kedua kelas yang terpilih. Teknik analisis data menggunakan metode tes dan observasi. Hasil penelitian ini mengungkapkan bahwa koefisien uji pengaruh untuk model problem-based learning berbantuan software cabri 3D V2 dapat meningkatkan kemampuan literasi numerasi sebesar 1,237538. Bagi peneliti selanjutnya, agar meneliti penggunaan model pembelajaraan yang lain berbantuan software matematika lainnya, agar dapat mengetahui adakah pengaruh untuk meningkatkan kemampuan literasi numerasi siswa pada jenjang SMP/sederajat. Kata kunci: Kemampuan literasi numerasi, model problem-based learning, software cabri $3 D$ V2
\end{abstract}

Copyright (c) 2021 Elok Rintarti Widiastuti, Meyta Dwi Kurniasih

$₫$ Corresponding author: Elok Rintarti Widiastuti

Email Address: rintartielok@gmail.com (Jl. Tanah Merdeka No 20, Jakarta Timur, Indonesia)

Received 12 Juni 2021, Accepted 19 Juni 2021, Published 23 Juni 2021

\section{PENDAHULUAN}

Literasi adalah sebuah kemampuan dan kecakapan yang wajib dikuasai oleh seseorang. Kemendikbud Indonesia sudah berusaha mempublikasikan mengenai persepsi literasi dasar untuk mewujudkan Pembangunan Nasional di era globalisasi. Masyarakat Indonesia wajib memiliki kemampuan enam literasi dasar yaitu literasi budaya dan kewargaan, literasi finansial, literasi sains, literasi bahasa, literasi digital, dan literasi numerasi (Tim GLN, 2017).

Kemampuan literasi dasar yang wajib dimiliki, salah satunya adalah literasi numerasi. Literasi numerasi adalah kemampuan seseorang menggunakan daya pikir yang logis untuk menganalisis suatu bacaan yang biasanya disajikan dalam bentuk grafik, tabel, bagan, gambar, dsb serta mengandung unsur- 
unsur matematika di dalamnya (Kementerian Pendidikan dan Kebudayaan, 2017).

The Programme International Student Assessment atau yang sering dikenal dengan PISA adalah sebuah rancangan yang diselenggarakan oleh OECD setiap 3 tahun sekali untuk melihat kemampuan membaca, matematika, dan sains dengan mengambil populasi anak berusia 15 tahun yang terdaftar dalam PISA. Untuk matematika, Pada tahun 2018 PISA mencatat bahwa Indonesia memperoleh skor rata-rata yaitu sebesar 379 dan berada di urutan ke-72 dari 78 negara (OECD, 2019, p. 7). Hal ini membuktikan bahwa adanya penurunan untuk skor rata-rata matematika yang semulanya di tahun 2015 Indonesia memperoleh skor rata-rata sebesar 386 dan berada di posisi ke-63 dari 70 negara (OECD, 2016, p. 177).

Penyebab literasi numerasi di Indonesia masih rendah yaitu kurang menariknya guru dalam mengemas model dan media pembelajaran yang dipakai. Pernyataan ini didukung oleh hasil penelitian Indah, Mania, \& Nursalam (2016) diterapkannya model pembelajaran yang sesuai. Pernyataan lain yang mendukung yaitu penelitian yang telah dilakukan oleh Yulianti, Jaya, \& Eliza (2019) dengan memberikan media pembelajaran yang tepat dapat memberikan solusi untuk meningkat kemampuan literasi numerasi Indonesia.

Untuk kegiatan proses pembelajaran matematika cukup banyak guru yang mengaplikasikan model pembelajaran cara lama yaitu pembelajaran yang masih di dominasi dan berpusat pada guru. Model pembelajaran cara lama tersebut masih banyak digunakan oleh guru karena dianggap lebih mudah dan lebih sederhana. Guru beranggapan bahwa kesuksesan pembelajaran dapat ditinjau dari penguasaannya dalam memberikan materi sesuai silabus. Akibatnya, tingkat pemahaman siswa terhadap kemampuan literasi numerasi rendah.

Pembekalan yang matang dan menguasai konseptual merupakan tantangan nyata untuk guru saat ini. Misalkan saja dalam pelajaran matematika, guru harus menekankan dan memotivasi siswa untuk menggunakan konseptual materi yang sudah diajarkan dalam penyelesaian masalah di kehidupan nyata. Sehingga, siswa tidak lagi merasa bahwa mempelajari matematika hanyalah sebuah pelajaran hitunghitungan yang tidak ada manfaatnya dan merasa sia-sia memepelajarinya. Maka dari itu, dibutuhkan model pembelajaran yang sesuai dan inovatif untuk dapat meningkatkan kemampuan literasi numerasi siswa.

Dengan mengaplikasikan model pembelajaran yang sesuai dan inovatif diharapkan dapat memberikan pengaruh positif kepada siswa, yaitu semakin meningkatnya kemampuan literasi numerasi siswa. Selain dituntut untuk memiliki kemampuan berhitung, siswa juga dituntut untuk dapat menguasai kemampuan literasi numerasi. Dalam kemampuan literasi numerasi, siswa diwajibkan untuk dapat mengolah data numerik seperti menganalisis dan memahami suatu pernyataan yang berkaitan dengan berbagai jenis angka dan simbol sebagai solusi permasalahan dalam aktifitas sehari-hari.

Model pembelajaran yang inovatif, adaptif dan sesuai kebutuhan ini dapat meningkatkan kemampuan literasi numerasi satu di antara yang ada adalah model problem-based learning. Model problem-based learning ditandai adanya penyajian masalah kontekstual yang disajikan oleh guru kemudian dibutuhkan keterampilan siswa dalam menganalisis dan memberikan solusi masalah tersebut. Sehingga dengan 
mengaplikasikan model problem-based learning, pembelajaran di dominasi dan berpusat pada siswa, serta siswa menjadi lebih familiar dengan soal-soal yang disajikan dalam permasalahan kontekstual.

Selain model pembelajaran, guru juga harus memikirkan media pembelajaran yang akan digunakan saat mengajar. Guru pun harus kreatif dalam mengajar matematika seperti halnya guru harus membuat alat peraga ataupun juga memperkenalkan software matematika yang dapat menunjang kemampuan literasi numerasi. Dengan menggunakan konsep seperti ini, maka akan dihasilkan suasana pembelajaran di kelas yang menyenangkan dan bisa merubah mindset buruk siswa terhadap pembelajaran matematika.

Menurut Ardilah (2020) mengatakan bahwa untuk mengatasi kendala tersebut, guru diharapkan mampu menciptakan iklim pembelajaran yang menyenangkan serta memanfaatkan media pembelajaran yang ada agar siswa memiliki semangat literasi tinggi dan mampu menghasilkan kegiatan pembelajaran yang bermakna, sehingga siswa dapat menyerap materi pembelajaran lebih maksimal dan dapat meningkatkan hasil belajarnya. Diharapkan dengan adanya penggunaan media pembelajaran dapat mengembangkan kemampuan literasi numerasi siswa.

Banyak sekali media pembelajaran yang bisa di aplikasikan pada saat pembelajaran matematika. Diantaranya yaitu software cabri $3 D$ V2. Software cabri $3 D$ V2 merupakan sebuah perangkat lunak matematika yang dapat dimanfaatkan sebagai media pembelajaran matematika khusunya geometri bangun dimensi tiga. Software cabri 3D V2 merupakan pengembangan dari software cabri sebelumnya. Dengan memanfaatkan software cabri $3 D \mathrm{~V} 2$, siswa dapat melihat gambar dan bentuk geometri bangun ruang dari berbagai arah dengan cara diputar menggunakan kursor ke posisi yang diinginkan. Adanya ilustrasi gambar yang divisualkan melalui software cabri $3 D$ V2 siswa dapat melihat jumlah titik, garis, atau bidang dari gambar bangun ruang yang diinginkan. Selain itu, siswa juga dapat mengetahui luas permukaan, volume, diagonal sisi, diagonal ruang, garis sejajar, dan garis tegak lurus, dan juga jaring-jaring dari bangun ruang. Dengan begitu, melalui software cabri $3 D$ V2 dapat membantu siswa mengatasi beberapa kesulitan saat belajar geometri bangun ruang dan dapat mendukung kegiatan penemuan serta dapat meningkatkan kemampuan literasi numerasi dalam pembelajaran matematika berbasis masalah. Berikut ini disajikan tampilan penggunaan software cabri $3 D$ V2.

Tabel 1. Tampilan penggunaan software cabri 3D V2

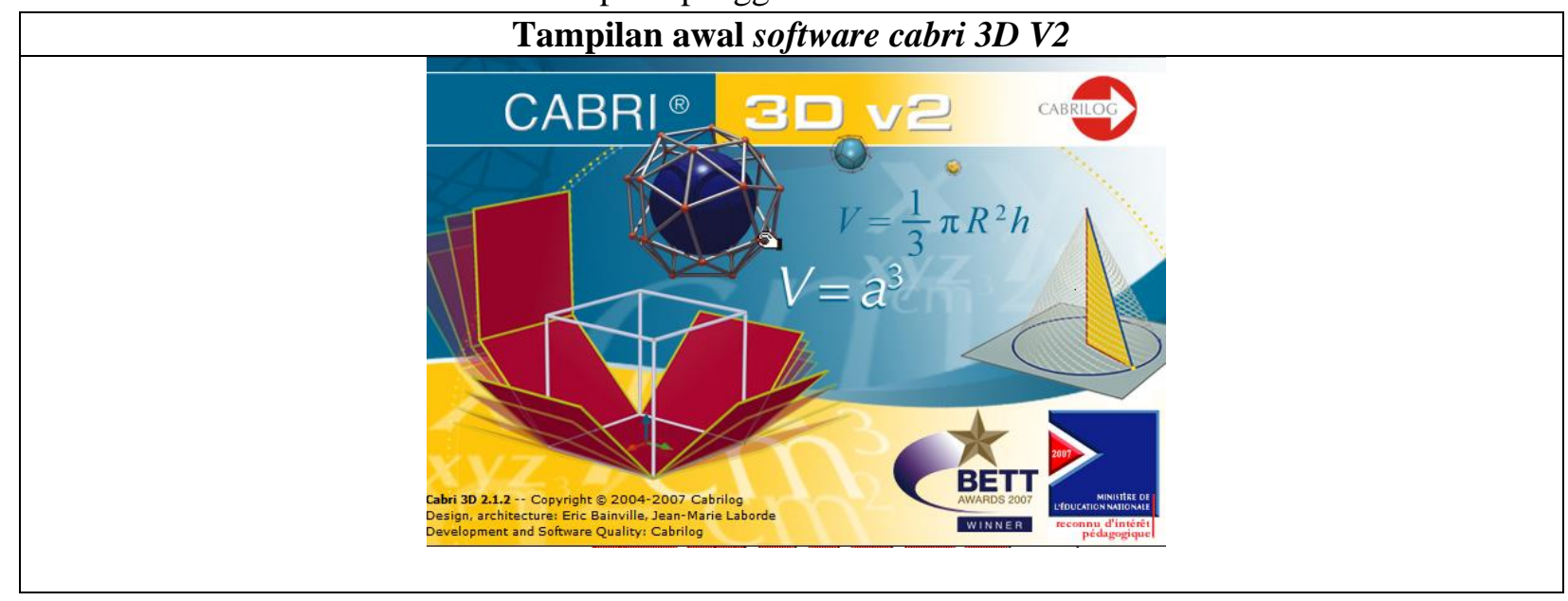




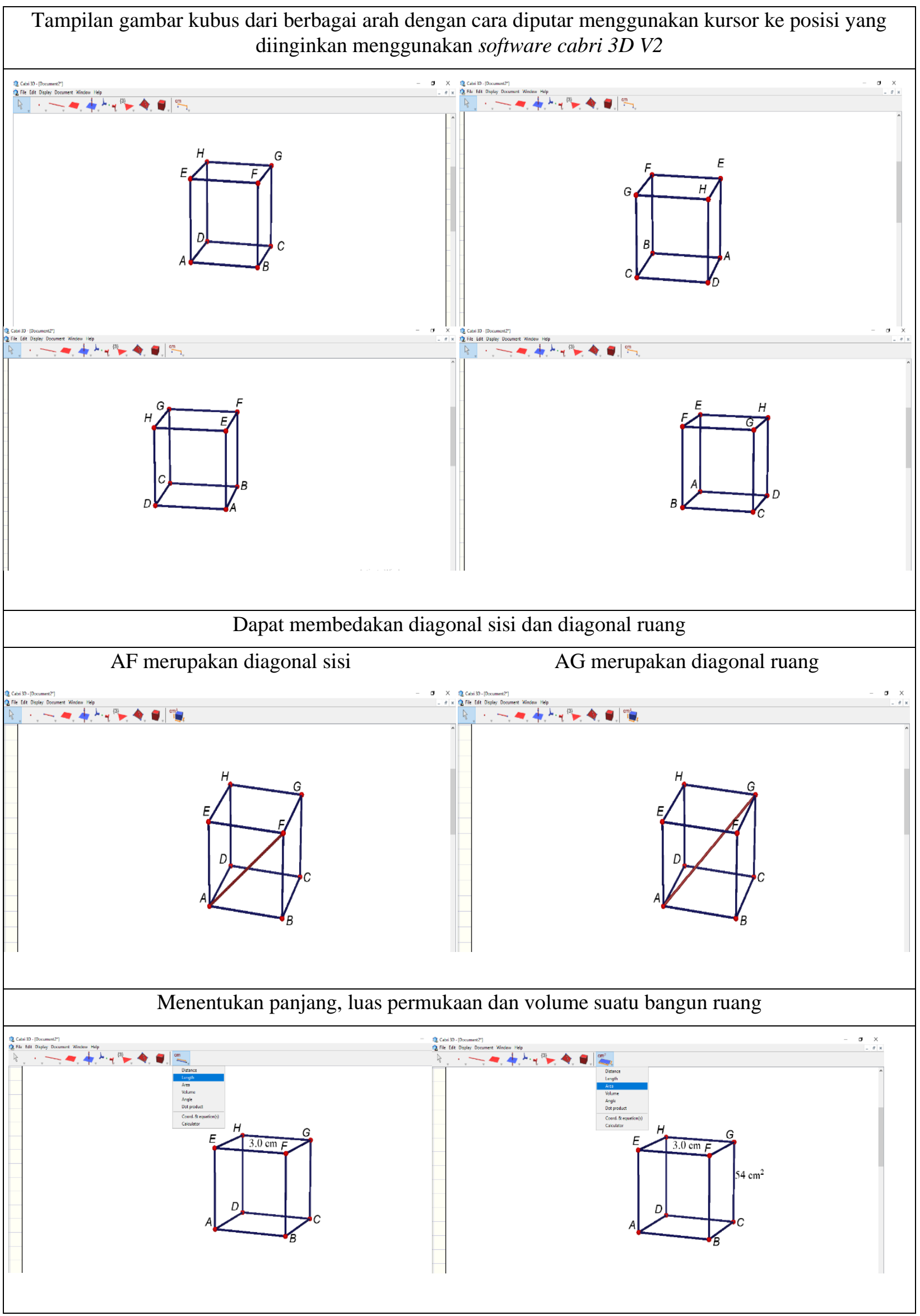




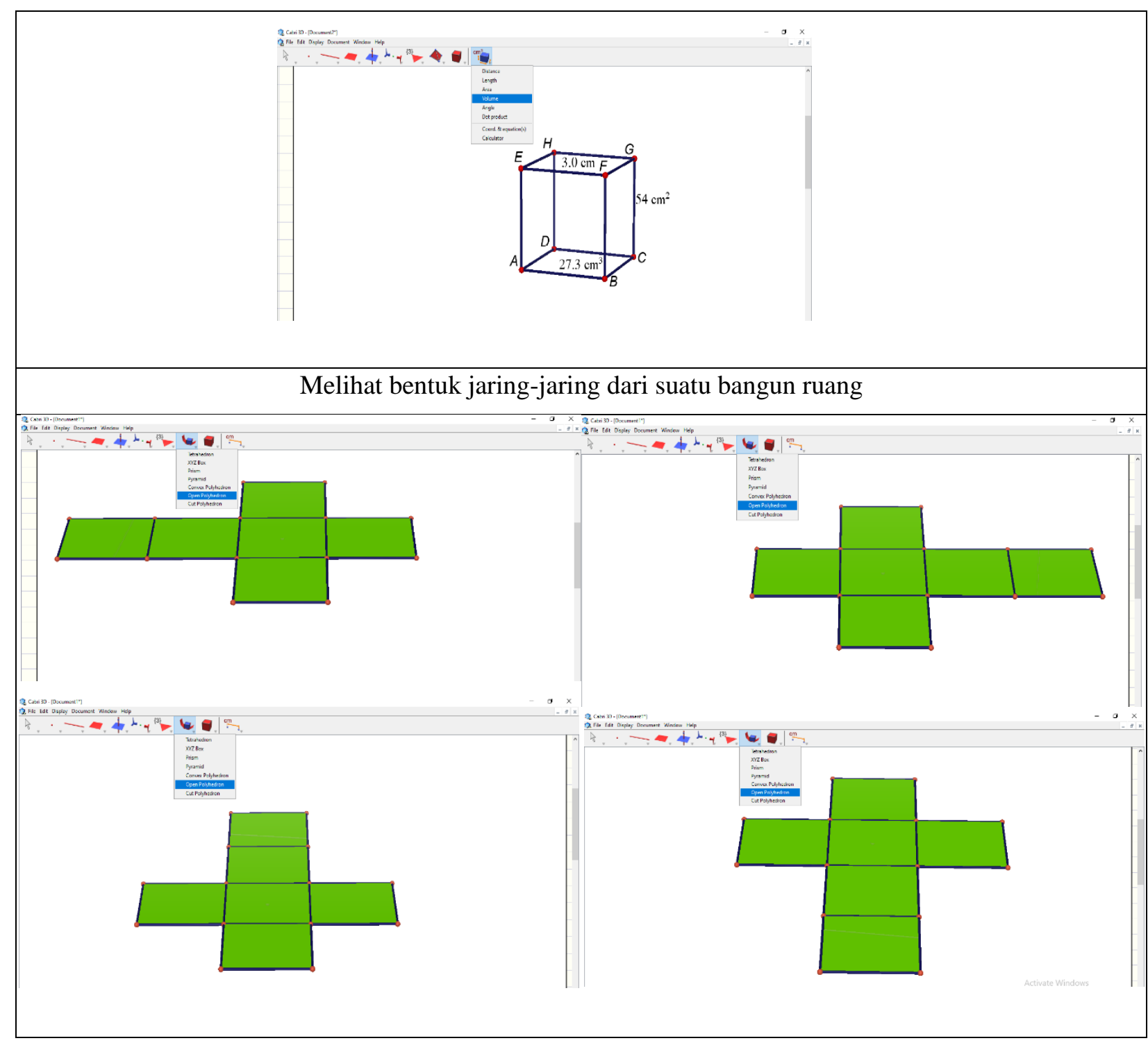

Dari paparan pembahasan di atas, peneliti ingin memanfaatkan model problem-based learning berbantuan software cabri $3 D$ V2 untuk mengembangkan kemampuan literasi numerasi siswa. Beberapa hasil penelitian yang mendukung dan menguatkan mengenai pengaplikasian model problem-based learning berbantuan software Cabri 3D diantaranya yaitu penelitian yang dilakukan oleh Supriatno, Bukhori, \& Saragih (2017) yang berjudul "Pengaruh Pembelajaran Berbasis Masalah Berbantuan Software Cabri 3D Terhadap Kemampuan Komunikasi Matematik dan Kemandirian Belajar Siswa MTS Negeri Tanah Jawa Kabupaten Simalungun" dengan adanya penerapan pembelajaran berbasis masalah berbantuan software cabri $3 D$ pada kelas eksperimen dapat meningkatkan kemampuan komunikasi matematik sebesar 31,844 dan meningkatkan kemandirian belajar siswa sebesar 11,064. Richi \& Mukhtar (2017) dengan judul "Perbedaan Kemampuan Pemahaman Konsep Matematika Siswa Menggunakan Model Pembelajaran Problem Based Learning dengan Model Pembelajaran Discovery Learning Berbantuan Cabri 3D di Kelas VIII SMP Negeri 27 Medan" menunjukkan kemampuan pemahaman konsep pada kelas eksperimen 1 yang mengaplikasikan model problem-based learning berbantuan cabri 3D memperoleh mean lebih tinggi yaitu 
sebesar 76,95 daripada kelas eksperimen 2 yang mengaplikasikan model discovery learning berbantuan cabri $3 D$ hanya memperoleh mean sebesar 68,175. Pitrini (2017) dengan judul "Pengembangan LKS Berbasis PBL Berbantuan Cabri 3D Materi Dimensi Tiga Kelas X SMA" menunjukkan pengembangan 5 produk LKS berbasis cabri $3 D$ materi dimensi tiga untuk kelas X SMA dapat meningkatkan hasil belajar siswa dengan dibuktikannya persentase siswa yang mengerjakn LKS tersebut sebesar 83,3\%.

Dan penelitian yang menguatkan lainnya adalah penelitian yang dilakukan oleh Marlena \& Nugraheni (2019) dengan berjudul "Probit Regression Analysis in Estimating the Effect of Learning Assisted by Cabri 3D on Students' Mathematical Understanding Ability" menunjukkan hasil analisis dengan menggunakan regresi probit dapat disimpulkan adanya peningkatan kemampuan pemahaman konsep matematika siswa, untuk kelas eksperimen yang mengaplikasikan media pembelajaran yaitu software cabri $3 D$ yang terintegrasi dengan model problem-based learning lebih tinggi yaitu mendapatkan mean sebesar 70 sedangkan kelas yang tanpa mengaplikasikan model problem-based learning berbantuan Cabri 3D hanya memperoleh mean sebesar 59. Pranawestu et al (2012) dengan judul "Keefektifan Problem Based Learning Berbantuan Cabri 3D Berbasis Karakter Terhadap Kemampuan Spasial” menunjukkan hasil pengaplikasian model problem-based learning berbantuan cabri $3 D$ berbasis karakter dapat meningkatkan KKM dan kemampuan spasial siswa yang ditandai dengan uji koefisien determinasi sebesar 50,30\%. Mardini, Marlena, \& Azhar (2019) dengan judul "Regresi Logistik Pada Model Problem Based Learning Berbantu Software Cabri 3D" menunjukkan hasil analisis dengan menggunakan regresi logistik dapat disimpulkan nilai Odds Ratio kelas eksperimen yang mengaplikasikan model problem-based learning berbantu software cabri $3 D$ dapat meningkatkan kemampuan pemahaman kosep matematis siswa sebesar 2,880 .

Untuk penelitian lainnya yang berkaitan dengan kemampuan literasi numersi siswa diantaranya adalah penelitian yang dilakukaan oleh Tyas \& Pangesti (2018) dengan judul "Menumbuhkembangkan Literasi Numerasi Pada Pembelajaran Matematika Dengan Soal HOTS" menyatakan bahwa hal utama dari pembelajaran matematika adalah penyelesaian permasalahan yang berkaitan dengan aktifitas sehari-hari sangat dibutuhkan yang terdapat pada soal-soal keterampilan tingkat tinggi atau sering disebut dengan soal HOTS. Yulianti et al (2019) dengan judul "Pengaruh Role Playing Terhadap Pengenalan Literasi Numerasi di Taman Kanak-kanak Twin Course Pasaman Barat" menyatakan bahwa adanya pengaruh penerapan model pembelajaran yang sesuai dan inovatif terhadap literasi numerasi anak dengan dibuktikannya kelas eksperimen yang memperoleh mean sebesar 87,5 sedangkan kelas kontrol memperoleh mean sebesar 78,5. Mahmud \& Pratiwi (2019) dengan judul "Literasi Numerasi Siswa Dalam Pemecahan Masalah Tidak Terstruktur" menyatakan bahwa adanya literasi numerasi siswa dalam memberikan solusi dan interpretasi dari penyajian soal berbasis konteks yang relevan.

Dan penelitian yang menguatkan lainnya adalah penelitian yang telah dilakukan oleh Hendrawati et al (2019) yang berjudul "Literasi Numerasi Berdasarkan Bahasa pada Suku Kowai Kabupaten Kaimana" menyatakan bahwa Suku Kowai telah menerapkan literasi numerasi bahasa etnomatematika dalam sistem penyebutan bilangan unik yang terdiri atas bilangan basis 5. Ratnasari (2020) yang berjudul "Outdoor 
Learning Terhadap Literasi Numerasi Anak Usia Dini” menyatakan bahwa outdoor learning dengan memanfaatkan alam terbuka sebagai metode pembelajaran sekaligus bermain dapat meningkatkan kemampuan literasi numerasi anak. Perdana \& Suswandari (2021) dengan judul "Literasi Numerasi Dalam Pembelajaran Tematik Siswa Kelas Atas Sekolah Dasar" menyatakan bahwa penerapan pembelajaran tematik untuk siswa kelas atas di sekolah dasar dapat memberikan rangsangan literasi numerasi siswa melalui media, metode, dan model pembelajaran yang diterapkan guru.

Dari berbagai hasil penelitian tersebut, sampai saat ini belum dibuktikan seberapa berpengaruh model problem-based learning berbantuan software cabri 3D V2 terhadap kemampuan literasi numerasi siswa, sehingga peneliti tertarik melakukan penelitian dengan judul "Pengaruh Model Problem Based Learning Berbantuan Software Cabri 3D V2 Terhadap Kemampuan Literasi Numerasi Siswa".

\section{METODE}

Metode eksperimen semu digunakan dalam penelitian ini dengan pendekatan kuantitatif dan mengambil bentuk posttest only control group design. Penelitian ini mengambil populasi siswa kelas 8 Sekolah Menengah Pertama Negeri 5 Tambun Selatan yang terdiri dari 14 kelas dengan jumlah mencapai 536 siswa dan teknik cluster random sampling dilakukan untuk dipilih sebanyak 2 kelas yang diperlukan untuk sampel penelitian. Terpilihnya kelas $8.8(\mathrm{H})$ sebanyak 40 siswa sebagai kelas kontrol dan kelas 8.9 (I) sebanyak 40 siswa sebagai kelas eksperimen diberi treatment berupa model problem-based learning berbantuan cabri 3D V2 yang dilaksanakan pada semester genap tahun ajaran 2020/2021.

Tes dan observasi dilakukan sebagai teknik pengumpulan data. Sebelum dilakukan penelitian, peneliti melakukan validasi ahli kepada dua dosen ahli untuk dianalisis kesesuaian kalimat yang digunakan dan uji validasi instrumen kepada 30 orang mahasiswa. Dalam penelitian, instrumen penelitian harus valid dan reliabel (Sugiyono, 2013, p. 122). Berdasarkan uji validasi ahli dan uji validasi instrumen bahwa instrumen tersebut layak untuk digunakan.

Data penelitian dianalisis menggunakan dua langkah. Langkah pertama adalah analisis data awal dan langkah kedua adalah analisis data observasi. Analisis data awal mencakup uji normalitas dan uji homogenitas menggunakan program komputer SPSS versi 25 untuk menguji apakah dua kelas tersebut berdistribusi normal dan homogen pada saat kondisi awal. Sedangkan untuk analisis data observasi mencakup uji normalitas, uji homogenitas, uji perbedaan rata-rata, uji-t, dan uji pengaruh (effect size) menggunakan program komputer SPSS versi 25 dan Microsoft Excel 2010 untuk melihat apakah nilai posttest kemampuan literasi numerasi kedua kelas tersebut normal dan homogen, serta melihat adanya pengaruh pemberian model problem-based learning berbantuan software cabri $3 D$ V2 pada kelas eksperimen. 


\section{HASIL DAN DISKUSI}

Penelitian ini dilaksanakan selama beberapa pertemuan. Berikut ini uraian langkah-langkah pelaksanaan pembelajaran menggunakan model problem-based learning berbantuan software cabri $3 D$ V2 yang dilakukan oleh peneliti:

- Memberikan stimulus dan motivasi

Sebelum memulai pembelajaran, peneliti memberikan stimulus dengan menyajikan gambar-gambar terkait bangun ruang sisi datar yang familiar bagi siswa. Peneliti menyajikan gambar rubik dan dadu untuk ilustrasi gambar kubus, serta menyajikan gambar akuarium dan kardus untuk ilustrasi gambar balok. Dari ilustarsi gambar tersebut, siswa diminta untuk mengamati gambar tersebut kemudian mengidentifikasikan sifat-sifat yang dimiliki oleh kubus dan balok serta diminta untuk menjelaskan perbedaan mandasar antara kubus dan balok. Kemudian, peneliti memberikan motivasi kepada siswa agar lebih peka terhadap lingkungan sekitar bahwa contoh nyata kubus dan balok ada dalam kehidupan. Dari sini siswa dapat berargumen bahwa matematika sangat dekat dengan kehidupan dan aktifitas sehari-hari.

- Orientasi siswa kepada masalah

Disajikan lembar kerja siswa. Siswa diminta untuk mengamati masalah yang ada di lembar kerja siswa tersebut.

- Mengorganisasi siswa untuk belajar

Peneliti membagi siswa menjadi 5 kelompok dimana satu kelompok berisi 8 anggota. Siswa diminta untuk menyelesaikan masalah yang terdapat pada lembar kerja siswa dan diperbolehkan menggunakan software cabri $3 D \mathrm{~V} 2$ untuk menyelesaikan masalah tersebut dengan cara mengkonstruksikan bangun ruang kubus dan balok yang disajikan sesuai dengan lembar kerja siswa. Siswa dapat menggunakan tools pada software cabri $3 D$ V2 yang telah dipelajari pada pertemuan sebelumnya.

- Membimbing penyelidikan individu dan kelompok

Peneliti menanyakan kendala yang dialami siswa dalam menyelesaikan soal pada lembar kerja siswa.

- Mengembangkan dan menyajikan hasil karya

Peneliti meminta siswa menyiapkan hasil diskusi kelompok dan meminta setiap kelompok memaparkan hasil diskusi.

- Menganalisa dan mengevaluasi proses pemecahan masalah

Peneliti meminta kelompok lain memberikan untuk memberikan tanggapan terhadap hasil diskusi kelompok penyaji dan ditutup dengan memberikan kesimpulan. Dengan adanya pelaksanaan pembelajaran menggunakan model problem-based learning berbantuan software cabri $3 D \mathrm{~V} 2$, siswa dapat menemukan asal usul rumus luas permukaan dan volume dari kubus dan balok. 


\section{Analisis Data Awal}

Sebelum dilakukan pembelajaran, peneliti menganalisis data hasil nilai matematika rapot semester 1 untuk melihat kondisi awal dari kelas kontrol dan kelas ekperimen menggunakan program komputer SPSS versi 25.

\section{Uji Normalitas}

Berdasarkan analisis uji normalitas hasil nilai matematika rapot semester 1 menggunakan program komputer SPSS versi 25 bahwa terdapat dua kolom pada tabel hasil uji normalitas yaitu uji normalitas Shapiro-Wilk dan uji normalitas Kolmogorov-Smirnov. Hasil uji normalitas dengan menggunakan ShapiroWilk untuk kelas kontrol memiliki sig hitung $0,253 \geq 0,05$ dan kelas eksperimen memiliki sig hitung 0,059 $\geq 0,05$ sedangkan uji normalitas dengan menggunakan Kolmogorov-Smirnov bahwa kelas kontrol memiliki sig hitung 0,089 $\geq 0,05$ dan kelas eksperimen memiliki sig hitung $0,087 \geq 0,05$. Kedua kelas tersebut berdistribusi normal dengan dibuktikannya bahwa baik uji normalitas menggunakan Shapiro-Wilk maupun Kolmogorov-Smirnov berada di atas nilai taraf signifikan 5\%.

\section{Uji Homogenitas}

Uji homogenitas dilakukan setelah uji normalitas. Berdasarkan analisis uji homogenitas hasil nilai matematika rapot semester 1 menggunakan program komputer SPSS versi 25 bahwa menghasilkan nilai sig sebesar $0,419 \geq 0,05$. Kedua kelas tersebut berada di atas nilai taraf signifikan 5\%, sehingga dapat diinterpretasikan homogen. Dengan demikian, untuk analisis data awal dapat diinterpretasikan kelas kontrol dan kelas eksperimen terbukti berdistribusi normal dan homogen.

\section{Analisis Data Observasi}

Setelah dilakukan analisis data awal yang mencakup uji normalitas dan uji homogenitas, maka dilakukannya pembelajaran dengan mengaplikasikan model problem-based learning berbantuan software cabri $3 D$ V2 kepada kelas ekperimen dan kelas kontrol tanpa diberikannya model problem-based learning berbantuan software cabri $3 D$ V2. Kemudian pada pertemuan terakhir, diberikannya posttest kemampuan literasi numerasi guna melihat apakah terdapat pengaruh pemberian model problem-based learning berbantuan software cabri $3 D$ V2 kepada kelas eksperimen. Setalah diberikannya posttest maka dilakukan analisis data observasi yang mencakup uji normalitas, uji homogenitas, uji-t, uji perbedaan rata-rata, dan uji pengaruh (effect size). Analisis data observasi menggunakan program komputer SPSS versi 25 dan Microsoft Excel 2010 untuk melihat apakah kelas kelas kontrol dan kelas eksperimen tersebut berdistribusi normal dan homogen setelah diberikan treatment berupa model problem-based learning berbantuan software cabri $3 D V 2$, serta untuk melihat seberapa pengaruh pemberian model problem-based learning berbantuan software cabri $3 D V 2$ terhadap kemampuan literasi numerasi siswa dilakukan melalui uji- $t$, perbedaan rata-rata, dan uji pengaruh (effect size).

\section{Uji Normalitas}

Berdasarkan analisis uji normalitas hasil nilai matematika rapot semester 1 menggunakan program komputer SPSS versi 25 bahwa terdapat dua kolom pada tabel hasil uji normalitas yaitu uji normalitas 
Shapiro-Wilk dan uji normalitas Kolmogorov-Smirnov. Hasil uji normalitas dengan menggunakan ShapiroWilk untuk kelas kontrol memiliki sig sebesar 0,60 $\geq 0,05$ dan kelas eksperimen memiliki sig sebesar 0,244 $\geq 0,05$ sedangkan uji normalitas dengan menggunakan Kolmogorov-Smirnov bahwa kelas kontrol memiliki sig hitung $0,200 \geq 0,05$ dan kelas eksperimen memiliki sig hitung $0,200 \geq 0,05$. Kedua kelas tersebut berdistrubusi normal dengan dibuktikannya bahwa baik uji normalitas menggunakan Shapiro-Wilk maupun Kolmogorov-Smirnov, kelas kontrol dan kelas eksperimen berada di atas nilai taraf signifikan 5\%.

\section{Uji Homogenitas}

Uji homogenitas dilakukan setelah uji normalitas. Berdasarkan analisis uji homogenitas nilai posttest kemampuan literasi numerasi siswa menggunakan program komputer SPSS versi 25 bahwa menghasilkan nilai sig $0,88 \geq 0,05$. Kedua kelas tersebut berada di atas nilai taraf signifikan 5\%, dapat diinterpretasikan homogen.

\section{Uji Perbedaan Rata-Rata}

Uji perbedaan rata-rata dilakukan untuk melihat perbandingan mean pada dua kelompok sampel. Berikut ini, hasil perbandingan mean yang disajikan dalam bentuk tabel menggunakan program komputer Microsoft Excel 2010.

Tabel 2. Deskripsi data posttest kemampuan literasi numerasi siswa menggunakan Microsoft Excel 2010

\begin{tabular}{|c|c|c|}
\hline & Kelas Kontrol & Kelas Eksperimen \\
\hline Jumlah Siswa & 40 & 40 \\
\hline Jumlah Nilai & 3108 & 3384 \\
\hline Mean & 77.7 & 84.6 \\
\hline Median & 78 & 85 \\
\hline Modus & 76 & 86 \\
\hline Varians & 31.08717949 & 58.09230769 \\
\hline Simpangan Baku & 5.575587815 & 7.621830993 \\
\hline
\end{tabular}

Selanjutnya dari tabel deskripsi data posttest kemampuan literasi numerasi siswa tersebut disajikan dalam bentuk histogram untuk melihat persebaran nilai kedua kelas.

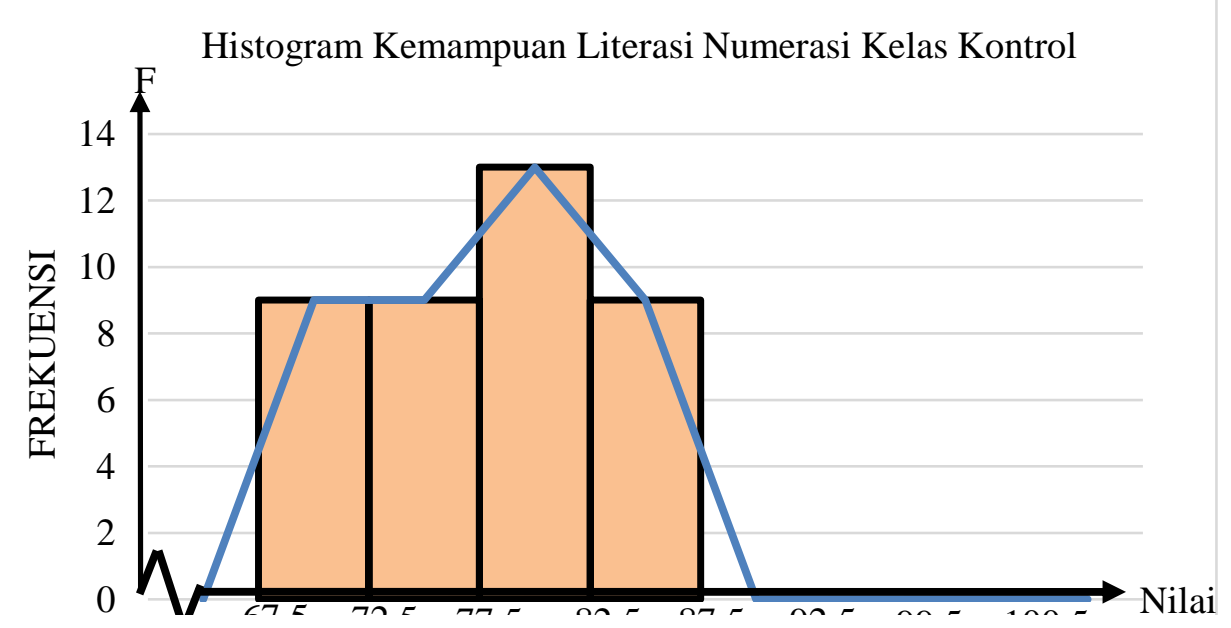

Gambar 1. Histogram kemampuan literasi numerasi (posttest) kelas kontrol menggunakan Microsoft Excel 2010 


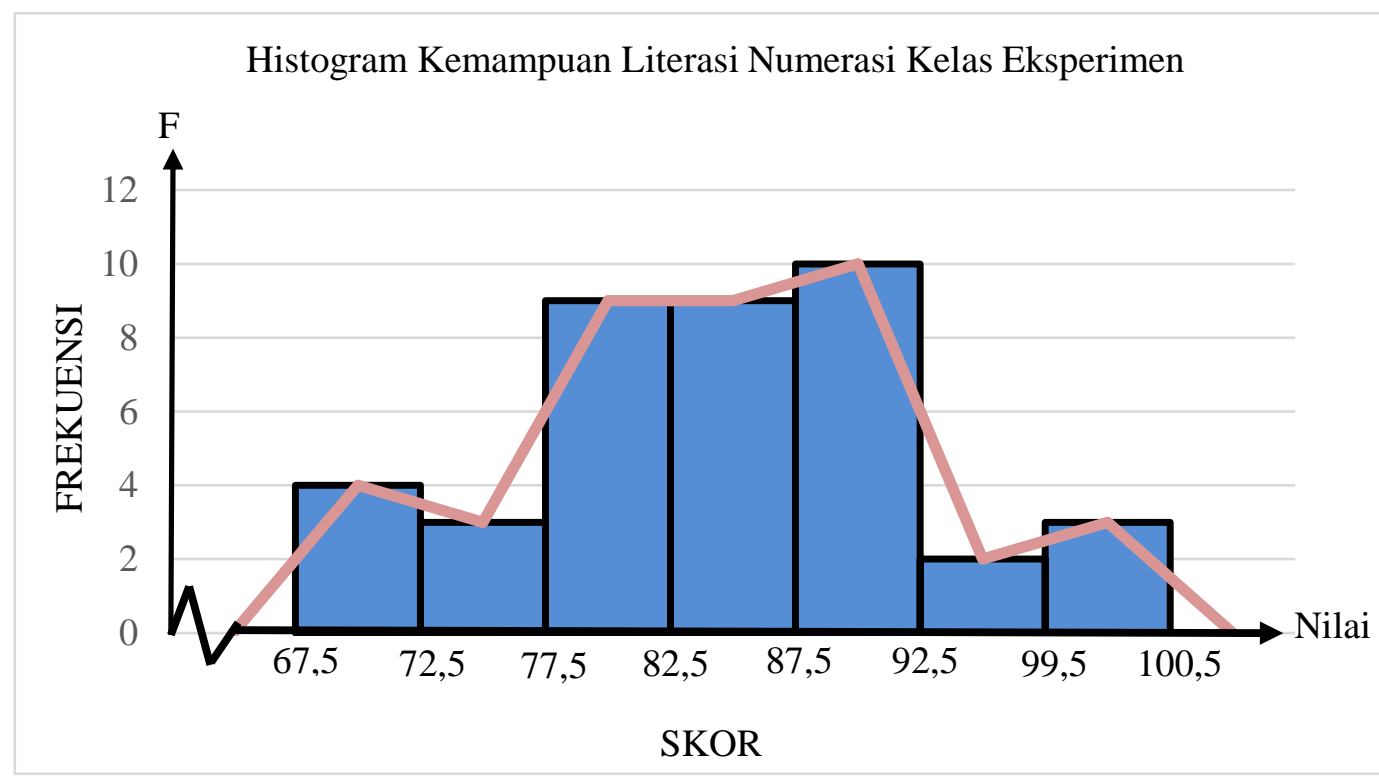

Gambar 2. Histogram kemampuan literasi numerasi (posttest) kelas eksperimen menggunakan Microsoft Excel 2010

Terlihat bahwa dari analisis uji perbedaan rata-rata terdapat perbedaan rata-rata yang signifikan pada kemampuan literasi numerasi siswa antara kelas eksperimen yang telah diberikan model problembased learning berbantuan software cabri $3 D$ V2 dan kelas kontrol yang tidak diberikan model problembased learning berbantuan software cabri $3 D$ V2. Hal tersebut ditunjukkan dari hasil mean kemampuan literasi numerasi kelas eksperimen sebesar 84,6 dan hasil mean kemampuan literasi numerasi kelas kontrol sebesar 77,7 .

Uji-t

Dengan mengacu kepada tabel deskripsi data, selanjutnya akan dilaksakan uji-t. Berdasarkan analisis uji-t program komputer Microsoft Excel 2010 bahwa menghasilkan $t$ hitung sebesar 4,621113 dan akan dibandingkan dengan $t$ tabel dengan derajat kebebasan 78 untuk taraf signifikan $5 \%=1,99085$. Sehingga, dapat diinterpretasikan bahwa $t_{\text {hitung }}>t_{\text {tabel }}(4.621113>1.99085)$ terdapat perbedaan terhadap kemampuan literasi numerasi siswa antara kelas eksperimen yang telah diberikan model problem-based learning berbantuan software cabri $3 D$ V2 dan kelas kontrol yang tidak diberikan model problem-based learning berbantuan software Cabri $3 D$ V2.

\section{Uji Pengaruh (Effect Size)}

Uji pengaruh (effect size) untuk melihatnya besarnya pengaruh model problem-based learning berbantuan software cabri $3 D$ terhadap kemampuan literasi numerasi siswa. Berdasarkan analisis uji pengaruh menggunakan program komputer SPSS versi 25 bahwa menghasilkan nilai koefisien sebesar $1,237538 \geq 0,8$. Dengan demikian, dapat diinterpretasikan bahwa besarnya pengaruh pengaplikasian model problem-based learning berbantuan software cabri $3 D$ V2 tergolong tinggi.

\section{KESIMPULAN}

Dari hasil dan diskusi di atas dapat diinterpretasikan bahwa model problem-based learning berbantuan software cabri $3 D$ V2 berpengaruh terhadap literasi numerasi siswa pada kelas 8 Sekolah 
Menengah Pertama Negeri 5 Tambun Selatan. Hal tersebut ditunjukkan dari uji pengaruh (effect size) menghasilkan nilai koefisien sebesar 1,237538 $\geq 0,8$ dengan kategori tinggi. Bagi peneliti selanjutnya, agar meneliti penggunaan model pembelajaraan yang lain berbantuan software matematika lainnya, agar dapat mengetahui adakah pengaruh untuk meningkatkan kemampuan literasi numerasi siswa pada jenjang SMP/sederajat.

\section{UCAPAN TERIMA KASIH}

Kami ucapkan terimakasih kepada Allah SWT, orangtua, kakak, adik, seluruh dosen Pendidikan Matematika UHAMKA, kepala sekolah dan guru serta siswa SMP Negeri 5 Tambun Selatan, teman-teman, dan seluruh partisipasi yang telah ikut serta dalam penelitian ini, sehingga penelitian ini diberikan kelancaran dan dapat diselesaikan dengan baik.

\section{REFERENSI}

Ardilah, N. (2020). Efektivitas media pembelajaran my classroom creation wall dalam meningkatkan kemampuan literasi sains peserta didik. 03(01).

Hendrawati, N. E., Muttaqin, N., \& Susanti, E. (2019). Etnomatematika : Literasi Numerasi Berdasarkan Bahasa pada Suku Kowai Kabupaten Kaimana. Prosiding Seminar Nasional Integrasi Matematika Dan Nilai Islami, 3(1), 239-243.

Indah, N., Mania, S., \& Nursalam, N. (2016). Peningkatan Kemampuan Literasi Matematika Siswa Melalui Penerapan Model Pembelajaran Problem Based Learning Di Kelas Vii Smp Negeri 5 Pallangga Kabupaten Gowa. MaPan, 4(2), 200-210. https://doi.org/10.24252/mapan.2016v4n2a4

Kementerian Pendidikan dan Kebudayaan. (2017). Materi Pendukung Literasi Numerasi. Journal of Chemical Information and Modeling, 8(9), 1-58.

Mahmud, M. R., \& Pratiwi, I. M. (2019). Literasi Numerasi Siswa Dalam Pemecahan Masalah Tidak

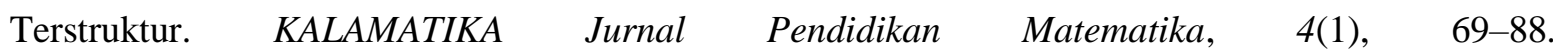
https://doi.org/10.22236/kalamatika.vol4no1.2019pp69-88

Mardini, N. I., Marlena, L., \& Azhar, E. (2019). Regresi Logistik Pada Model Problem Based Learning Berbantu Software Cabri 3D. Jurnal Mercumatika, 4(1), 64-70. https://doi.org/https://doi.org/10.26486/jm.v4i1.839

Marlena, L., \& Nugrheni, E. A. (2019). Probit Regression Analysis in Estimating the Effect of Learning Assisted by Cabri 3D on Students' Mathematical Understanding Ability. Al-Jabar : Jurnal Pendidikan Matematika, 10(2), 319-326. https://doi.org/10.24042/ajpm.v10i2.4729

OECD. (2016). PISA 2015 Results.

OECD. (2019). Insights and Interpretations.

Perdana, R., \& Suswandari, M. (2021). Literasi Numerasi Dalam Pembelajaran Tematik Siswa Kelas Atas Sekolah Dasar. Absis: Mathematics Education Journal, $3(1), \quad 9$. https://doi.org/10.32585/absis.v3i1.1385 
Pitriani. (2017). Pengembangan lks berbasis pbl berbantuan cabri 3d materi dimensi tiga kelas x sma. FIBONACI (Jurnal Pendidikan Matematika Dan Matematika), 3(1982), 1-10. https://doi.org/https://doi.org/10.24853/fbc.3.1.1-10

Pranawestu, A., Kharis, M., Mariani, S., Matematika, J., Matematika, F., \& Alam, P. (2012). KEEFEKTIFAN PROBLEM-BASED LEARNING BERBANTUAN CABRI 3D BERBASIS KARAKTER TERHADAP KEMAMPUAN SPASIAL Info Artikel Abstra. 1(2252). https://doi.org/https://doi.org/10.15294/ujme.v1i2.1094

Ratnasari, E. M. (2020). Outdoor Learning Terhadap Literasi Numerasi Anak Usia Dini. ThufuLA: Jurnal Inovasi Pendidikan Guru Raudhatul Athfal, 8(2), 182-192. https://doi.org/10.21043/thufula.v8i2.8003

Richi, N., \& Mukhtar. (2017). Perbedaan Kemampuan Pemahaman Konsep Matematika Siswa Menggunakan Model Pembelajaran Problem Based Learning Dengan Model Pembelajaran Discovery Learning Berbantuan Cabri 3D Di Kelas Viii Smp Negeri 27 Medan. Inspiratif: Jurnal Pendidikan Matematika, 3(1), 86-95. https://doi.org/10.24114/jpmi.v3i1.8886

Sugiyono, P. D. (2013). Metode Penelitian Kuantitatif, Kualitatif, dan R\&D.

Supriatno, Bukhori, \& Saragih, S. (2017). Pengaruh Pembelajaran Berbasis Masalah Berbantuan Software Cabri 3D Terhadap Kemampuan Komunikasi Matematik dan Kemandirian Belajar Siswa MTs Negeri Tanah Jawa Kabupaten Simalungun. Tabularasa PPS UNIMED, 14(1), 67-78. https://doi.org/https://doi.org/10.24114/jt.v14i1.9014

Tim GLN. (2017). Panduan Gerakan Literasi Nasional.

Tyas, F., \& Pangesti, P. (2018). Menumbuhkembangkan Literasi Numerasi Pada Pembelajaran Matematika Dengan Soal Hots. Indonesian Digital Journal of Mathematics and Education, 5, 566-575.

Yulianti, E., Jaya, I., \& Eliza, D. (2019). Pengaruh Role Playing terhadap Pengenalan Literasi Numerasi di Taman Kanak-kanak Twin Course Pasaman Barat. Aulad: Journal on Early Childhood, 2(2), 41-50. https://doi.org/10.31004/aulad.v2i2.33 